\title{
Hepatosplenic Candidiasis: Successful Treatment with Fluconazole
}

Carol A. Kauffman, M.D., Suzanne F. Bradley, M.D., Stephen C. Ross, M.D., DAVID R. WEBER, M.D., Ann Arbor, Michigan

PURPOSE: To determine if fluconazole is effective treatment for hepatosplenic candidiasis that has not resolved with amphotericin B and flucytosine treatment.

PATIENTS AND METHODS: Six patients (ages 3 to 44) with acute leukemia and hepatosplenic candidiasis who did not respond to prior antifungal therapy were treated with fluconazole.

RESULTS: All six patients had fever and three had nausea and vomiting; computed tomographic (CT) scan showed lucencies in the liver in six, lucencies in the spleen in five, and lucencies in the kidneys in three. Prior therapy with 1.6 to 4 $g$ of amphotericin $B$ in the five adults and 526 mg of amphotericin B in the child (with the addition of flucytosine in four) failed to improve clinical symptoms or lucencies in the liver, spleen, and kidneys seen on CT scan. Fluconazole was given at a dose of 200 to $400 \mathrm{mg}$ daily (70 to $100 \mathrm{mg}$ in the child) for 2 to 14 months. All patients had resolution of fever and other symptoms in 2 to 8 weeks. Improvement of the lesions noted on CT scan was seen in 4 to 8 weeks in all patients. Total resolution of lesions noted on CT scan occurred by 4 weeks in two patients, but took 4 to 5 months for three patients and 13 months for one patient. Three patients had relapse of their acute leukemia and two died, presumably cured of their candidiasis. Two patients underwent successful bone marrow transplantation without relapse of their candidiasis.

CONCLUSION: Fluconazole appears to be useful in the treatment of hepatosplenic candidiasis that has not resolved with amphotericin $B$ and flucytosine therapy.
From the Division of Infectious Diseases, Department of Internal Medicine, Veterans Administration Medical Center, and University of Michigan Medical School. Ann Arbor, Michigan.

Requests for reprints should be addressed to Carol A. Kauffman, M.D. Veterans Administration Medical Center, 2215 Fuller Road, Ann Arbor, Michigan 48105.

Manuscript submitted September 24, 1990, and accepted in revised form February 17, 1991.
A distinct clinical syndrome, hepatosplenic candidiasis, appears to be increasing in immunocompromised hosts [1-5]. This form of candidiasis, characterized by focal persistent microabscesses in liver, spleen, and sometimes in kidneys, usually occurs in patients with acute leukemia who have recovered from neutropenia. These patients present with fever, abdominal pain, anorexia, nausea, and vomiting [3-5]. This form of candidiasis has been very difficult to treat, many times persisting after months of therapy [5].

We report on six patients with this syndrome who continued to be ill despite treatment with amphotericin B. All six were treated with fluconazole and had eradication of their Candida infection.

\section{PATIENTS AND METHODS}

Six patients with culture- and/or histopathologic-documented hepatosplenic candidiasis were treated from January 1989 to July 1990. All had been treated with amphotericin $\mathrm{B}$, four had received flucytosine, and two had received ketoconazole prior to use of fluconazole. Failure of prior antifungal therapy was defined as persistent fever, persistent or worsening liver lesions on computed tomographic (CT) scan of the abdomen, and persisting or progressing clinical symptoms. Informed consent was obtained from all patients or parents in the case of the child. Clinical symptoms and laboratory parameters were followed every 2 to 4 weeks for the duration of therapy with fluconazole.

Treatment with fluconazole was begun at a dose of $200 \mathrm{mg}$ orally daily and increased to $400 \mathrm{mg}$ orally daily after several weeks in all of the adults; the child received $70 \mathrm{mg}$ intravenously daily and then was switched to $100-\mathrm{mg}$ tablets after 3 months. The drug was administered intravenously in two adults when nausea and vomiting precluded oral intake. Fluconazole levels were not measured in these patients.

\section{RESULTS}

\section{Clinical Features}

The ages of the six patients ranged from 3 to 44 years. All had acute leukemia, which was in remission when hepatosplenic candidiasis was diagnosed. All six had fever as the primary symptom of their illness, three had nausea and vomiting, two had hepatomegaly, and one had right upper quadrant 


\section{TABLE I}

Clinical Characteristics and Response to Prior Antlfungal Therapy

\begin{tabular}{|c|c|c|c|c|c|c|c|c|}
\hline \multirow{2}{*}{$\begin{array}{l}\text { Patient } \\
\text { Number }\end{array}$} & \multirow[b]{2}{*}{ Age/Sex } & \multirow[b]{2}{*}{ Sites } & \multirow[b]{2}{*}{ CT Scan } & \multirow[b]{2}{*}{ Pathology } & \multirow[b]{2}{*}{ Culture } & \multicolumn{3}{|c|}{ Prior Treatment (duration) } \\
\hline & & & & & & $\mathrm{AmB}^{*}$ & $5-F C$ & Keto \\
\hline 1 & $32 / M$ & $L, S$ & $L, S(+)$ & $L(t)$ & $L(+)$ & 1.5 months & - & 2 weeks \\
\hline 2 & $44 / F$ & $L, K$ & $L, K(+)$ & $L(-)$ & $L(-)$ & 6 months & - & - \\
\hline 3 & $36 / F$ & $L, S, K$ & $L, S, K(+)$ & $L(+)$ & $L(-)$ & 3 months & 3 months & - \\
\hline 4 & $3 / F$ & $L, S, K$ & $L, S, K(+)$ & $L(+)$ & $L(+)$ & $\begin{array}{l}2 \text { months } \\
(526 \mathrm{mg})\end{array}$ & 2 months & - \\
\hline 5 & $44 / M$ & $L, S$ & $L, S(+)$ & $L(+)$ & $L(-)$ & 3 months & 3 months & 1 month \\
\hline 6 & $18 / M$ & $L, S$ & $L, S(+)$ & $s(+)$ & $S(-)$ & $\begin{array}{l}2.5 \text { months } \\
(2.9 \mathrm{~g})\end{array}$ & 2.5 months & - \\
\hline
\end{tabular}

$\mathrm{AmB}=$ amphotericin $\mathrm{B} ; 5-\mathrm{FC}=$ flucytosine; Keto $=$ ketoconazole $\mathrm{L}=$ liver; $\mathrm{S}=$ spleen; $\mathrm{K}=$ kidneys.

* Number in parentheses $=$ total dose of amphotericin $B$.

\begin{tabular}{|c|c|c|c|c|c|}
\hline \multirow{2}{*}{$\begin{array}{l}\text { Patient } \\
\text { Number }\end{array}$} & \multicolumn{2}{|c|}{ Fluconazole Therapy } & \multicolumn{2}{|c|}{ Response to Therapy } & \multirow[b]{2}{*}{ Outcome } \\
\hline & $\overline{D o s e}(\mathrm{mg})$ & Duration & Clinical & CT Scan & \\
\hline 1 & $\begin{array}{l}200 \\
400^{*}\end{array}$ & $\begin{array}{l}2 \text { weeks } \\
1.5 \text { months }\end{array}$ & $\begin{array}{l}\text { Fever resolved-Week } 3 \text {; nausea, } \\
\text { vomiting worse, fever returned } \\
\text { (due to leukemia) }\end{array}$ & Normal-Week 4 & $\begin{array}{l}\text { Candidiasis resolving; leukemia } \\
\text { relapsed and patient died }\end{array}$ \\
\hline 2 & $\begin{array}{l}200 \\
400^{*}\end{array}$ & $\begin{array}{l}2 \text { weeks } \\
1.5 \text { months }\end{array}$ & $\begin{array}{l}\text { Fever resolved-Week } 4 \text {; nausea, } \\
\text { vomiting resolved - Week } 6\end{array}$ & $\begin{array}{l}L \text { improved, } K \text { worse- } \\
\text { Week } 6 ; L \text { normal, } K \\
\text { worse-Week } 8 ; L, K \\
\text { normal- Week } 14\end{array}$ & $\begin{array}{l}\text { Candidiasis resolved; BM Tx } 5 \\
\text { months after therapy } \\
\text { stopped-no relapse of } \\
\text { candidiasis }\end{array}$ \\
\hline 3 & $\begin{array}{l}200 \\
400\end{array}$ & $\begin{array}{l}2 \text { weeks } \\
5.5 \text { months }\end{array}$ & $\begin{array}{l}\text { Fever resolved-Week } 6 \text {; nausea, } \\
\text { vomiting resolved-Week } 8\end{array}$ & $\begin{array}{l}\text { Improved-Week } 8 \\
\text { normal-Month } 5\end{array}$ & $\begin{array}{l}\text { Candidiasis resolved; leukemia } \\
\text { relapsed and patient died }\end{array}$ \\
\hline 4 & $\begin{array}{l}70^{*} \\
100\end{array}$ & $\begin{array}{l}3 \text { months } \\
11 \text { months }\end{array}$ & Fever resolved-Week 8 & $\begin{array}{l}\text { Improved-Week } 5 ; \\
\text { improved-Week } 11 ; \\
\text { normal-Month } 5\end{array}$ & $\begin{array}{l}\text { Candidiasis resolved; leukemia in } \\
\text { remission }\end{array}$ \\
\hline 5 & $\begin{array}{l}200 \\
400\end{array}$ & $\begin{array}{l}6 \text { weeks } \\
11 \text { months }\end{array}$ & Fever resolved-Week 4 & $\begin{array}{l}\text { Improved_Week 6; } \\
\text { improved_Month 5; } \\
\text { normal-Month } 13\end{array}$ & $\begin{array}{l}\text { Candidiasis resolved; leukemia } \\
\text { relapsed after fluconazole } \\
\text { stopped }\end{array}$ \\
\hline 6 & $\begin{array}{l}200 \\
400\end{array}$ & $\begin{array}{l}2 \text { weeks } \\
3 \text { months }\end{array}$ & $\begin{array}{l}\text { Fever intermittent prior to } \\
\text { fluconazole; felt better by Week } \\
2\end{array}$ & Normal-Week 4 & $\begin{array}{l}\text { Candidiasis resolved; BM Tx in } \\
\text { Week } 10 \text { of therapy-no relapse } \\
\text { of candidiasis }\end{array}$ \\
\hline
\end{tabular}

$\mathrm{L}=$ liver; $\mathrm{K}=$ kidneys; $\mathrm{BM} \mathrm{Tx}=$ bone marrow transplantation.

* Intravenous fluconazole was given at the dose indicated for 10 days (Patient 1), 8 days (Patient 2), and 3 months (Patient 4).

pain. The sites of involvement were liver (six), spleen (five), and kidneys (three) (Table I).

\section{Diagnostic Studies}

Four of the six patients had the diagnosis established by liver biopsy, which showed abscesses with yeast and hyphal forms characteristic of Candida, and one patient had a splenectomy, which revealed multiple abscesses with Candida. Only two of the five tissue specimens yielded Candida albicans when cultured. The sixth patient had a percutaneous liver biopsy, which did not show fungi, but she had already received 2 months of amphotericin B therapy. However, she previously had Candida tropicalis grown from blood and skin lesions 3 months prior to the liver biopsy, characteristic lucencies in the liver and kidney on a CT scan of the abdomen, and persistent fever, nausea, and vomiting. None of the other patients had documented candidemia at any point during their treatment for acute leukemia.

CT scans of the abdomen showed characteristic multiple lucencies in the liver in all patients, with involvement of spleen and kidneys noted less frequently (Table I). At the time of diagnosis of hepatosplenic candidiasis, white blood cell counts varied widely $(1,800 / \mu \mathrm{L}$ to $35,000 / \mu \mathrm{L})$, but were low only in the 3-year-old girl. The alkaline phosphatase level was abnormal in all but one patient (114 U/L to 701 $\mathrm{U} / \mathrm{L})$. The bilirubin level was elevated in only one patient, and the alanine aminotransferase and aspartate aminotransferase values were within normal limits in all six.

\section{Prior Antifungal Therapy}

All six patients had been treated with amphotericin B for as long as 1.5 to 6 months, and four received flucytosine concomitantly (Table I). The to- 
tal dose of amphotericin $B$ received by the five adults was 1.6 to $4 \mathrm{~g}$ (mean $=2.9 \mathrm{~g}$ ), and the 3 -yearold patient received a total of $44 \mathrm{mg} / \mathrm{kg}$. Two patients received ketoconazole, one for 2 weeks and one for 4 weeks.

Fever persisted in all the patients throughout their course of amphotericin B therapy; Patient 6 had only intermittent low-grade fevers, but the other five patients had daily spiking elevations of temperature. Five patients had persistently elevated alkaline phosphatase values. CT scanning showed persistence of lucencies in the liver in two patients and increased number and size of lesions in four patients. Laparotomy after 4 months of therapy with amphotericin B/flucytosine and then ketoconazole in Patient 5 showed multiple liver abscesses with fungi noted on histopathologic examination.

\section{Response to Fluconazole Therapy}

All six patients responded to treatment with fluconazole (Table II). Symptoms of fever, nausea and vomiting, and abdominal pain resolved within 3 to 8 weeks. Patient 1 had initial resolution of fever, then recurrence in the fourth week, but this was most likely due to a relapse of his acute leukemia, which progressed to cause his death in Week 9 of therapy.

The level of alkaline phosphatase was not useful in all patients as a measure of response to therapy. In two patients, decreasing alkaline phosphatase values correlated with clinical and CT scan improvement. However, in two others the values fell to normal, only to increase again, probably related to a relapse of leukemia. The child had persistently elevated levels, presumably due to bone growth.

The timing of repeated CT scans was decided by the patient's primary physician so that the actual time of resolution of lesions was not established in most patients. In two patients, the CT scan was normal by Week 4 of therapy; in four patients, improvement in the lesions in the liver was noted by Weeks 5 to 8 of therapy (Figure 1). Two of these four patients showed complete resolution of lucencies on CT scan after 5 months of therapy. The response of Patient 5 was difficult to evaluate because scans were done so infrequently; 13 months after fluconazole treatment was begun, his CT scan was normal. Patient 2 had resolution of lesions in the liver by Week 8 , but worsening kidney lesions during this time, with final resolution by Week 14 .

Three patients had relapse of their acute leukemia. Patient 1 died of leukemia, and his candidiasis appeared to be resolved but no necropsy was performed. Patient 3 tolerated reinduction chemotherapy, had resolution of candidiasis, but then had another relapse of leukemia and died. Patient 5 had gradual resolution of his candidiasis (by Week 8 , symptoms resolved and a CT scan improved, with a
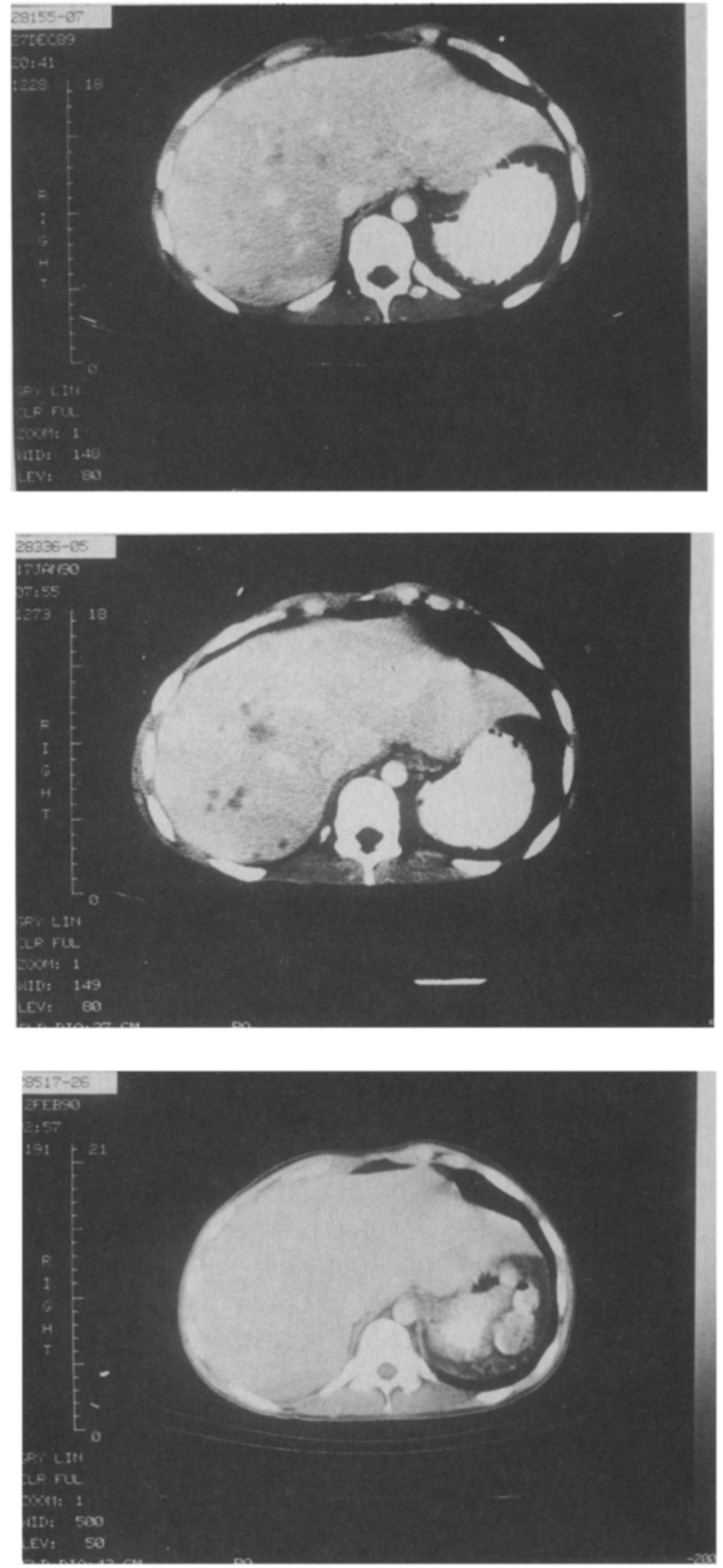

Figure 1. CT scans of the abdomen in Patient 6. Top, multiple lucencies in the liver after amphotericin $B$ and flucytosine had been given for 2 months (December 27, 1989); middle, after 5 days of fluconazole therapy, there is no change and perhaps worsening of the liver lesions (January 17, 1990); bottom, after 1 month of fluconazole therapy, lesions have resolved completely (February 12, 1990).

normal CT scan documented by Month 13 of therapy with fluconazole), and then had a relapse of leukemia after fluconazole administration had been stopped.

Two patients underwent successful bone marrow transplantation without relapse of their candidia- 
sis-one in Month 3 of therapy and one 5 months after therapy had been stopped. Patient 4 had resolution of her candidiasis during maintenance chemotherapy and has done well with no relapse of her leukemia.

The length of therapy was determined by several factors, including the clinical response to therapy, the status of the leukemia, and patient decisions. For example, the two patients who received less than 3 months of therapy did so because one had relapse of leukemia, was not treated with a further course of chemotherapy, and died soon after $(\mathrm{Pa}$ tient 1), and the other patient elected to stop therapy because she believed that fluconazole had caused her to have a seizure (Patient 2). Other patients were treated until both clinical and CT scan resolution had occurred, and two were treated for over a year because they were doing well and their physicians believed it best to continue therapy to be certain of cure of their infection.

No side effects of fluconazole therapy were noted. It was not believed that the seizure experienced by Patient 2 was related to fluconazole, especially since a lesion was noted on magnetic resonance imaging scan in an area corresponding to her focal seizure activity.

\section{COMMENTS}

Hepatosplenic candidiasis has become a major problem in the population of patients with acute leukemia who have undergone successful induction chemotherapy and whose disease is in remission. The development of abdominal complaints and fever may herald the development of this syndrome [3-5]. CT scan or ultrasound examination will usually show the characteristic lesions in liver, spleen, and kidneys [6], and biopsy will show yeast and hyphal forms characteristic of Candida in areas with varying amounts of necrosis and granulomatous inflammation. Interestingly, cultures taken from involved tissues are often negative [5]. Despite negative cultures, symptoms persist and the patient will not improve without antifungal therapy. Given the fact that many of these patients will require further markedly immunosuppressive procedures, such as bone marrow transplantation, to definitively treat their leukemia, eradication of visceral foci of Candida is essential.

An as yet unexplained aspect of this syndrome is the poor response to therapy with antifungal drugs $[4,5,7,8]$. The five adults described in this report had received from $1.6 \mathrm{~g}$ to $4.0 \mathrm{~g}$ of amphotericin $B$ with minimal clinical or radiographic improvement. It is possible, however, that higher daily doses or a longer course of therapy with amphotericin B might have led to resolution of infection in these patients.
Thaler et al [5] describe a patient who required amphotericin B therapy for 14 months before finally achieving cure. There is suggestive clinical and experimental animal evidence that the combination of amphotericin $B$ and flucytosine may be more effective than amphotericin B alone [5,9]; four of our patients had received both drugs and still did not respond. The experience with ketoconazole, although limited, has not been encouraging $[4,5]$.

In contrast, the experience with liposomal amphotericin $B$ has been very encouraging. LopezBerestein et al [7] found that 13 of 17 patients with hepatosplenic candidiasis responded to liposomal amphotericin B therapy. Standard antifungal therapy had failed in all of these patients. The liposomal preparation allows very large doses of amphotericin $B$ to be given with minimal or no toxicity, and high concentrations of drug are achieved in organs of the reticuloendothelial system, such as the liver and spleen $[10,11]$. A similar excellent response to therapy with a different liposomal amphotericin B preparation has been noted by Sculier et al [12]. However, only a limited amount of liposomal amphotericin B is available for experimental clinical use at this time. A similar preparation, amphotericin B-lipid complex, is currently undergoing limited trials in the treatment of fungal infections and may prove to be useful.

All of our patients responded to fluconazole after not responding to other antifungal therapy. In several, the response was dramatic with prompt resolution of clinical symptoms; in others, response occurred very slowly after several months of therapy. Resolution of lesions on CT scan was slower than clinical improvement, and the alkaline phosphatase level was not as helpful for following the response to therapy as the clinical and radiologic parameters.

No relapses of candidiasis occurred, even though several patients experienced relapse of leukemia and were given reinduction chemotherapy. The appropriate total duration of therapy is not clear. Whether the long course of therapy (more than 1 year in two patients) prevented relapse of candidiasis is not clear. It seems prudent to continue to treat throughout the time of maximum immunosuppression, such as occurs with intensive chemotherapy and bone marrow transplantation. Interestingly, Patient 2 stopped taking the drug herself at a time when her physicians believed she may still have had active candidiasis. Five months later, she underwent bone marrow transplantation and did not have a recurrence of candidiasis.

Although this report concerns only a small number of patients, the response to fluconazole therapy was encouraging, and similar to that reported by others $[8,13]$. Why fluconazole should be effective 
when amphotericin $B$ was not is not clear. It is possible that prior therapy with amphotericin $B$ was essential to resolution of hepatosplenic candidiasis in these patients. Perhaps persistence of amphotericin B in the liver well after therapy was stopped contributed to the eventual resolution of infection [14]. Whether fluconazole should be used as primary therapy for this disease has not been answered by this study and would require a multicenter randomized trial comparing amphotericin $B$ with fluconazole.

\section{ACKNOWLEDGMENT}

Pfizer-Roerig generously supplied fluconazole for the patients reported herein. We thank Drs. Jeffrey Band and Duane Harrison for providing data on their patients.

\section{REFERENCES}

1. Jones JM. Granulomatous hepatitis due to Candida albicans in patients with acute leukemia. Ann Intern Med 1981; 94; 475-7.

2. Wald BR, Ortege JA, Ross L, Wald $P$, Lang WE, Williams KO. Candidal splenic abscesses complicating acute leukemia of childhood treated by splenectomy Pediatrics 1981; 67: 296-9.

3. Tashijan LS, Abramson JS, Peacock JE. Focal hepatic candidiasis: a distinct clinical variant of candidiasis in immunocompromised patients. Rev Infect Dis
1984; 6: 689-703

4. Haron E, Feld R, Tuffnell P, Patterson B, Hasselback R, Matlow A. Hepatic candidiasis: an increasing problem in immunocompromised patients. Am J Med 1987; 83: 17-26.

5. Thaler M, Pastakia B, Shawker TH, O'Leary T, Pizzo PA. Hepatic candidiasis in cancer patients: the evolving picture of the syndrome. Ann Intern Med 1988; 108: $88-100$

6. Pastakia B, Shawker TH, Thaler M, O'Leary T, Pizzo PA. Hepatosplenic candidiasis: wheels within wheels. Radiology 1988; 166: 417-21.

7. Lopez-Berestein G, Bodey GP, Fainstein V, et al. Treatment of systemic fungal infections with liposomal amphotericin B. Arch Intern Med 1989; 149: 2533-6. 8. Jakab K, Kelemen E, Prinz G. Torok I. Amphotericin-resistant invasive hepatosplenic candidiasis controlled by fluconazole. Lancet 1990; 335: 473-4. 9. Thaler M, Bacher J, O'Leary T, Pizzo PA. Evaluation of single-drug and combination antifungal therapy in an experimental model of candidiasis in rabbits with prolonged neutropenia. J Infect Dis 1988; 158: 80-8.

10. Meunier $F$. New methods for delivery of antifungal agents. Rev infect Dis 1989; 11: \$1605-12.

11. Lopez-Berestein G, Hopfer RL, Mehta R, Mehta K, Hersh EM, Juliano RL. Liposome encapsulated amphotericin $B$ for treatment of disseminated candidiasis in neutropenic mice. J infect Dis 1984; 150: 278-83.

12. Sculier JP, Coune A, Meunier F, et al. Pilot study of amphotericin B entrapped in sonicated liposomes in cancer patients with fungal infection. Eur $\mathrm{J}$ Cancer Clin Oncol 1988; 24: 527-38.

13. Bodey G, Anaissie E, Keating M, Kantarjian H. Chronic systemic candidiasis treated successfully with fluconazole [abstract 72]. In: Proceedings of the 7th International Symposium on Infections in the Immunocompromised Host, Peebles, Scotland, 1990.

14. Christiansen KJ, Bernard EM, Gold JWM, Armstrong D. Distribution and activity of amphotericin B in humans. J Infect Dis 1985; 152: 1037-43. 